University of Nebraska - Lincoln

DigitalCommons@University of Nebraska - Lincoln

P. F. (Paul Frazer) Williams Publications

Electrical \& Computer Engineering, Department

February 2005

\title{
Electrochemical self-assembly of porous alumina templates
}

\author{
V. Sadasivan \\ University of Nebraska - Lincoln \\ C. P. Richter \\ University of Nebraska - Lincoln \\ L. Menon \\ Texas Tech University, Lubbock, TX \\ P. F. Williams \\ University of Nebraska - Lincoln, pfw@moi.unl.edu
}

Follow this and additional works at: https://digitalcommons.unl.edu/elecengwilliams

Part of the Electrical and Computer Engineering Commons

Sadasivan, V.; Richter, C. P.; Menon, L.; and Williams, P. F., "Electrochemical self-assembly of porous alumina templates" (2005). P. F. (Paul Frazer) Williams Publications. 42.

https://digitalcommons.unl.edu/elecengwilliams/42

This Article is brought to you for free and open access by the Electrical \& Computer Engineering, Department of at DigitalCommons@University of Nebraska - Lincoln. It has been accepted for inclusion in P. F. (Paul Frazer) Williams Publications by an authorized administrator of DigitalCommons@University of Nebraska - Lincoln. 
Published in AIChE Journal 51:2 (February 2005), pp. 649-655; doi 10.1002/aic.10332

Copyright (C) 2005 American Institute of Chemical Engineers; published by John Wiley, Inc.

Used by permission. http://www.interscience.wiley.com

Submitted December 26, 2003; revised June 16, 2004; published online January 14, 2005.

\title{
Electrochemical self-assembly of porous alumina templates
}

\author{
V. Sadasivan \& C. P. Richter \\ Department of Chemical Engineering, University of Nebraska-Lincoln, Lincoln, NE 68588 \\ L. Menon \\ Department of Physics, Texas Tech University, Lubbock, TX 79409 \\ P. F. Williams \\ Department of Electrical Engineering, University of Nebraska-Lincoln, Lincoln, NE 68588; \\ email: pfw@moi.unl.edu (Corresponding author)
}

\begin{abstract}
Porous alumina templates are fabricated by anodization of $\mathrm{Al}$ in an acid. The characteristics of the template, such as the pore diameter, interpore separation, and the periodicity of the porous structure depend on the conditions of anodization and the acid that is used as electrolyte. The variation of pore diameter and interpore separation as a function of anodization parameters are described. The use of porous alumina templates as masks to assemble nanoarrays is an important application and the deposition of $\mathrm{Au}$ nanodots on a surface of silicon is discussed.
\end{abstract}

Keywords: porous alumina, nanodots, electrochemistry, nanotechnology, self assembly

\section{Introduction}

Porous alumina forms on the surface of aluminum in a selforganized manner when anodized in an acid under specific conditions. Such templates have recently emerged as an important self-assembly method for nanofabrication. ${ }^{1-6}$ They can be used in different ways to synthesize self-assembled arrays of nanowires and nanodots of a variety of materials, such as metals, alloys, binary compounds, and multilayers. Characterization of these materials can easily be achieved by releasing the nanowires from the template. Magnetic, electric, transport, and optical measurements all contribute toward the exploration of the fundamental properties of nanostructured materials and point toward their technological potential. Alumina templates have high porosities $\left(\sim 10^{11}\right.$ pores $\left./ \mathrm{cm}^{2}\right)$. They can easily be prepared in the laboratory with good control over the size (length and diameter) of the pores. Under certain conditions, very good periodicity of the pore arrangement can also be obtained. Porous alumina templates can also withstand high temperatures, which may be necessary in some cases to anneal the deposited material. In our laboratory, we have successfully used the porous alumina method in the preparation of nanoparticles of various magnetic, superconducting, and semiconducting materials. ${ }^{7-11}$ In this paper we review the process for fabrication of porous alumina templates. The conditions of anodization that control the various parameters of the film are discussed. Scanning electron microscopy (SEM), transmission electron microscopy (TEM), and atomic force microscopy (AFM) images of the porous templates are presented for the various fabrication conditions.

\section{Experimental Details}

The nature of the aluminum oxide formed on the surface of aluminum depends on the conditions of anodization. ${ }^{12,13}$ Anodization of aluminum in a neutral solution ( $\mathrm{pH}$ 5-7) leads to formation of a flat nonporous aluminum oxide film, commonly called a barrier-type film. Anodization in an acid $(\mathrm{pH}<4)$ results 


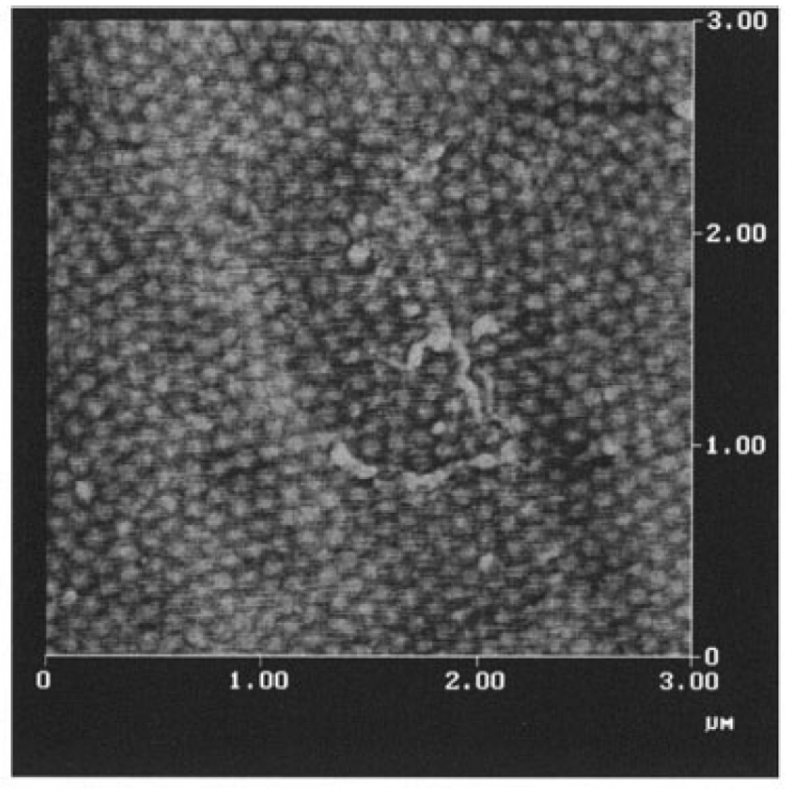

(a)

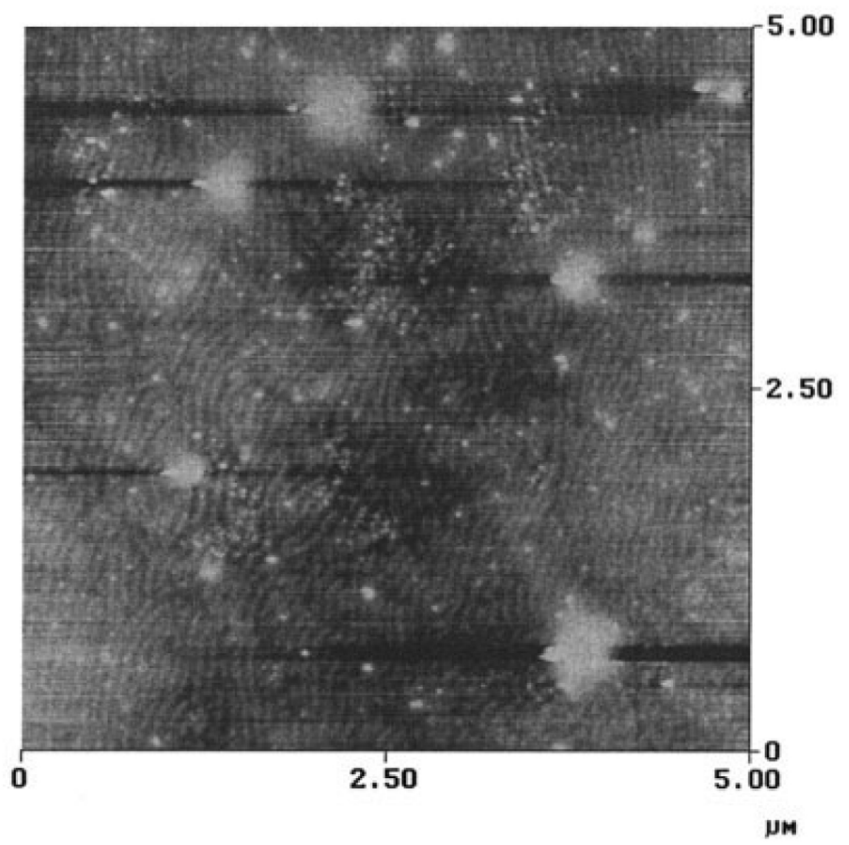

(b)

Figure 1. Atomic force micrograph of an $\mathrm{Al}$ foil electropolished at 60 $\mathrm{V}$ for $30 \mathrm{~s}$, showing the formation of arrays of (a) dots and (b) wires. The interdot and interwire distance is of the order of $100 \mathrm{~nm}$.

in a porous aluminum oxide film. Depending on the acid used, the $\mathrm{pH}$ of the acid and the anodization voltage, it is possible to control the diameter of the pores and the interpore separation. The complete process for the synthesis of porous alumina is described below.
A $99.99 \% \mathrm{Al}$ foil is ultrasonically degreased in trichloroethane solution. This is followed by electropolishing the $\mathrm{Al}$ foil in an electrolyte commonly called the L1 electrolyte, which consists of $1050 \mathrm{~cm}^{3}$ ethyl alcohol, $150 \mathrm{~cm}^{3}$ butyl cellosolve, 93 $\mathrm{cm}^{3}$ perchloric acid, and $205 \mathrm{~cm}^{3}$ distilled water. Electropolishing is carried out under DC conditions with the $\mathrm{Al}$ foil placed at the anode. Anodic dissolution of a metal under specific polishing conditions involves both electrical and chemical phenomena. It has been shown by Bandyopadhyay et al. ${ }^{14}$ that, depending on the electropolishing conditions, one can obtain an array of dots or wires on the surface of the aluminum. Later, Konovalov et al. ${ }^{15}$ showed that the topography not only depends on the electropolishing conditions but also on the surface crystalline orientation. They found that an $\mathrm{Al}(110)$ surface always exhibits a regular striped array. The $\mathrm{Al}(111)$ and $\mathrm{Al}$ (100) surfaces do not exhibit stripes but the pattern is usually hexagonally ordered. These highly ordered patterns may be used as a mask for the synthesis of nanodots or nanowires. Figure 1 shows an AFM image of an array of dots and wires formed at different regions of a polycrystalline $\mathrm{Al}$ foil, electropolished at $60 \mathrm{~V}$ for about $30 \mathrm{~s}$ in 5-s intervals. Dilute bromine/methanol solution may be used to mildly etch the surfaces to preferentially remove the troughs and leave behind the crests. ${ }^{16}$ This will produce an array of isolated nanodots on the surface of $\mathrm{Al}$.

The electropolished Al surface may be anodized in an acid to produce porous alumina. The acids typically used as electrolytes are $15 \%$ sulfuric acid, $3 \%$ oxalic acid, $5 \%$ chromic acid, and $5 \%$ phosphoric acid. Al foil is used as the anode and a $\mathrm{Pt}$ mesh as the cathode. A DC voltage is then applied across the two electrodes. During anodization in acid, a layer of aluminum oxide forms as in the case of neutral solutions. However, the aluminum oxide is simultaneously locally dissolved by hydrogen ions assisted by the applied electric field.

The chemical reactions involved in the porous oxide growth are:

At the Anode

$2 \mathrm{Al}+3 \mathrm{H}_{2} \mathrm{O}=\mathrm{Al}_{2} \mathrm{O}_{3}+6 \mathrm{H}^{+}+6_{\mathrm{e}}^{-}$
$($Dissolution of Alumina)
$\mathrm{Al}_{2} \mathrm{O}_{3}+6 \mathrm{H}^{+}=2 \mathrm{Al}^{3+}+3 \mathrm{H}_{2} \mathrm{O}$
At the Cathode
$6 \mathrm{H}^{+}+6_{\mathrm{e}}^{-}=3 \mathrm{H}_{2}$

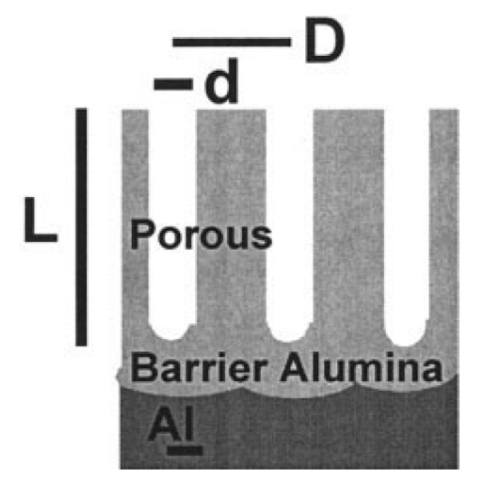

Figure 2. Schematic diagram of the cross section of a porous alumina template. 
(a)

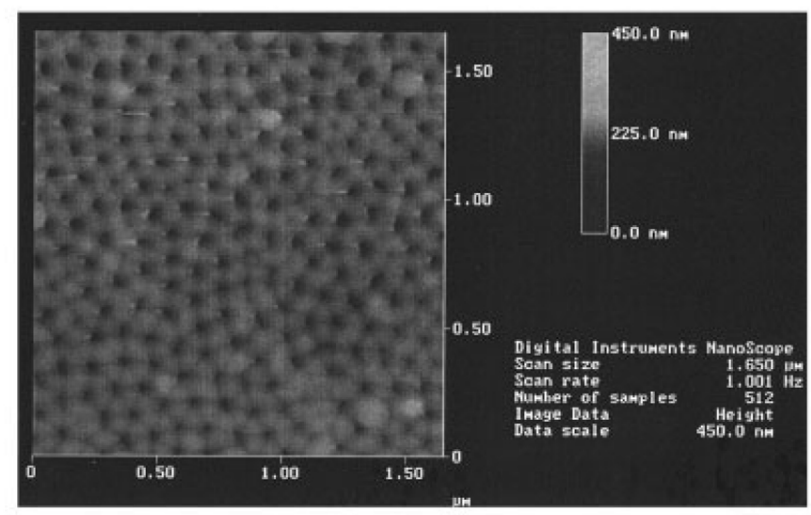

(b)

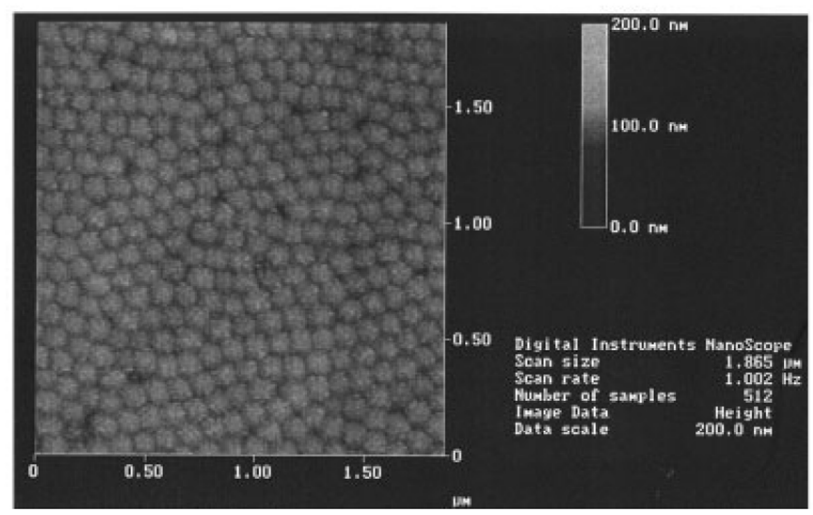

(c)

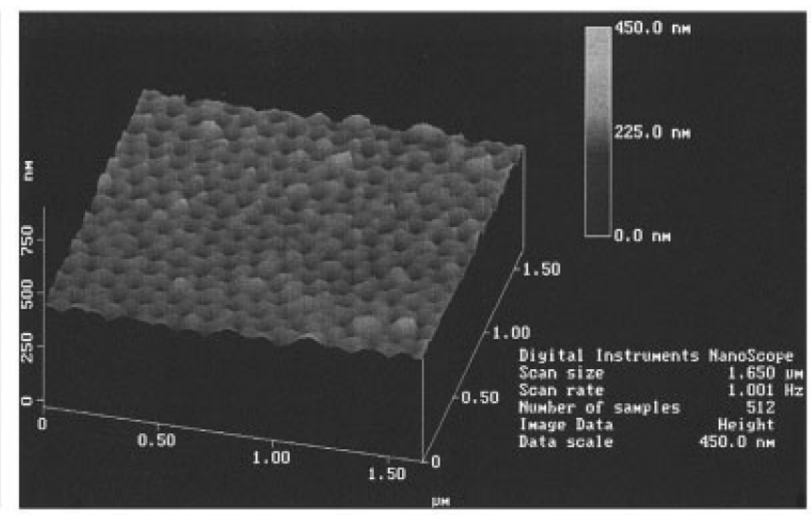

(d)

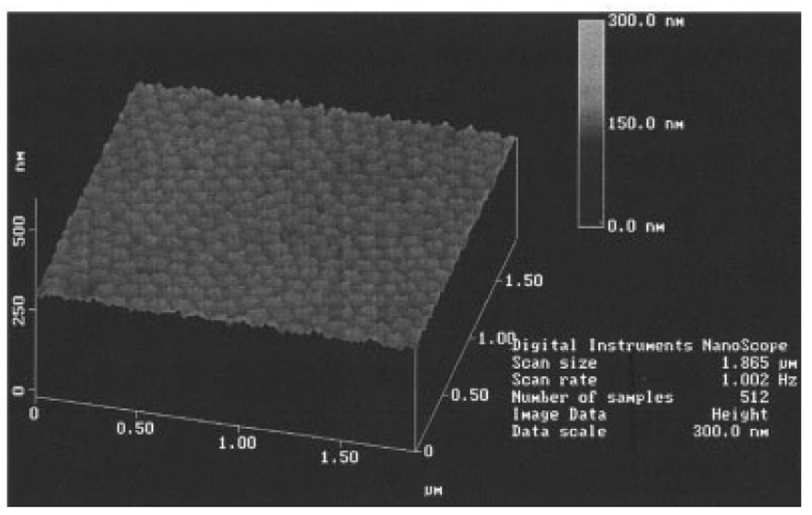

Figure 3. AFM image of (a) the top and (b) bottom surfaces of a porous template.The template was prepared by anodization in $3 \%$ oxalic acid at $40 \mathrm{~V}$.

The pores grow perpendicular to the surface of the $\mathrm{Al}$ and are open at the top. At the bottom, interfacing the $\mathrm{Al}$ surface, there is a thin barrier layer of aluminum oxide. Unlike the nonporous film grown in neutral solutions the $\mathrm{Al} /$ barrier interface in the porous films are curved rather than flat (see schematic diagram in Figure 2). AFM images of the top and bottom of the porous templates are shown in Figure 3. The images were obtained for a sample anodized in $3 \%$ oxalic acid at $40 \mathrm{~V}$. The dark regions are the pores, whereas the lighter areas are the surrounding alumina. The images are consistent with the fact that only the top layer is porous, whereas the bottom layer is nonporous.

Several models have been presented concerning the growth of the porous aluminum oxide in an acid. ${ }^{17-23}$ The basic idea is that an equilibrium of two competing mechanisms, that is, electric field-enhanced oxide dissolution at the oxide/electrolyte interface and oxide growth at the metal/oxide interface, are responsible for the formation of the pore growth perpendicular to the surface. The oxide growth is attributed to the migration of oxygen containing ions $\mathrm{O}^{2-} / \mathrm{OH}^{-}$from the electrolyte through the oxide layer at the pore bottom. The oxide dissolution arises from the migration of $\mathrm{Al}^{3+}$ ions that drift through the oxide layer and are ejected into the electrolyte. The elementary processes involved in the porous oxide growth are shown in Figure 4. $\mathrm{Al}^{3+}$ ions that are lost to the electrolyte are responsible for porous oxide growth, whereas $\mathrm{Al}^{3+}$ ions that reach the oxide/electrolyte interface contribute to oxide formation in the case of barrier oxide growth.

\section{Results and Discussion}

To investigate the variation of pore diameter and interpore separation as a function of anodization voltage and the strength of the acid used, SEM, TEM, and AFM images were obtained for various templates prepared by anodization under different conditions. The following solutions were used for the anodization: $5 \%$ phosphoric acid, $3 \%$ oxalic acid, $5 \%$ chromic acid, and $15 \%$ sulfuric acid. The samples prepared by anodization in $15 \%$ sulfuric acid have the smallest diameters, whereas the samples prepared in 5\% phosphoric acid have the largest diameters. SEM images were obtained for the samples with larger pore diameters $(>50 \mathrm{~nm})$. For pore diameters smaller than 50 $\mathrm{nm}$, TEM images were obtained.

Figure 5 shows SEM images of porous templates prepared by anodization in $5 \%$ phosphoric acid at three different voltages, 120,80 , and $40 \mathrm{~V}$. For these measurements, the sample was anodized for about $10 \mathrm{~min}$. The surface was then coated with a thin layer $(\sim 10-20 \mathrm{~nm})$ of Au. This is done to create a conducting layer at the surface so that the electrons do not produce surface charging. The diameter is of the order of $200 \mathrm{~nm}$ 


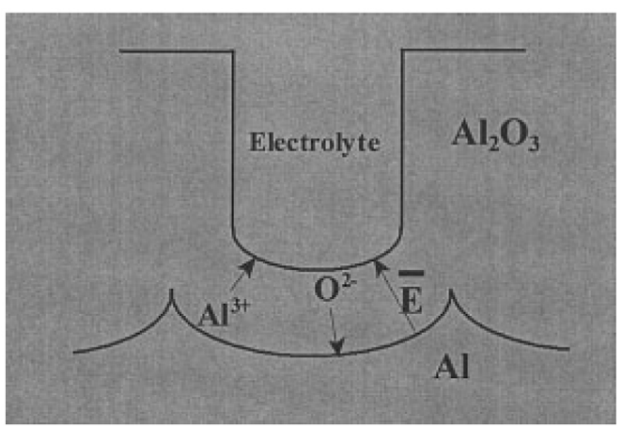

Figure 4. Elementary processes during pore growth. Movement of $\mathrm{Al}^{3+}$ ions through the oxide layer into electrolyte and movement of $\mathrm{O}^{2-}$ to pore bottom.

for an anodization voltage of $120 \mathrm{~V}, 100 \mathrm{~nm}$ for an anodization voltage of $80 \mathrm{~V}$, and $60 \mathrm{~nm}$ for an anodization voltage of 40 $\mathrm{V}$. The pore diameters are not very uniform, nor are they periodic. Also, from the figure, it is clear that the pore formation is better at higher anodization voltages. Better pore formation at smaller voltages may be obtained using other acids.

Porous alumina templates prepared by anodization in 3\% oxalic acid exhibit smaller pore diameters. Figure 6 shows TEM images of samples prepared by anodization at 10 and 5 V. To prepare the samples for TEM, the following method was used. The sample was anodized for about $20 \mathrm{~min}$. The top surface of the sample was covered with an organic material. The sample was then immersed in saturated $\mathrm{HgCl}_{2}$ solution to remove the bottom layer of aluminum. The bottom barrier layer of aluminum oxide below the porous layer was then thinned by soaking in 5\% phosphoric acid. This was done to create a more or less transparent film so that the transmitted electrons could pass through. The results for the samples prepared in 3\% oxalic acid display the pore diameter to be about $15 \mathrm{~nm}$ for an anodization voltage of $5 \mathrm{~V}$ (Figure 6a), which increases to about $25 \mathrm{~nm}$ for anodization voltage of $10 \mathrm{~V}$ (Figure 6b) and to about $50 \mathrm{~nm}$ for anodization voltage of $40 \mathrm{~V}$ (Figure 8). For samples anodized in 5\% chromic acid, the pore diameter is of the order of 70-100 nm (Figure 7). This is of the same order of magnitude as the diameter of the pores formed by anodization in 3\% oxalic acid (see AFM image in Figure 3).

It may be noted that the best periodicity is obtained for the sample anodized at $40 \mathrm{~V}$ in $3 \%$ oxalic acid. In fact, for this sample, it has been observed that the range of periodicity can be improved by a two-step anodization process. ${ }^{23-26}$ In this process, the sample is first anodized for a long time (about 10 $12 \mathrm{~h}$ ). This long-time anodization allows the formation of wellordered pore arrays and also reduces the number of defects. The thick layer of alumina is removed in a mixed solution of $0.4 \mathrm{MH}_{3} \mathrm{PO}_{4} / 0.2 \mathrm{MH}_{2} \mathrm{Cr}_{2} \mathrm{O}_{4}$. The sample is then reanodized for the required time interval. The AFM image of such a two-step anodized template is shown in Figure 8. The sample exhibits perfect periodicity in the range of microns. One may extend the range of periodicity by increasing the anodization time in the first step. Such well-ordered pore structures with smaller and larger pore diameters may be obtained by anodization in sulfuric acid at lower voltages and phosphoric acid at larger voltages,

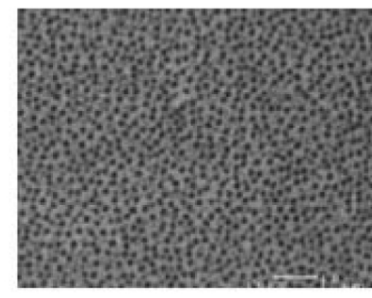

(a)

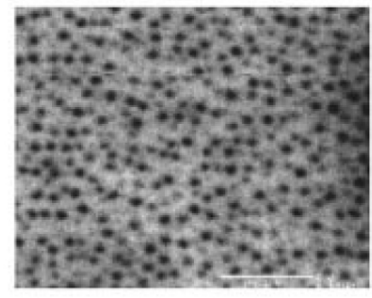

(b)

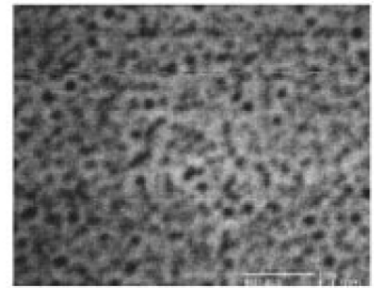

(c)

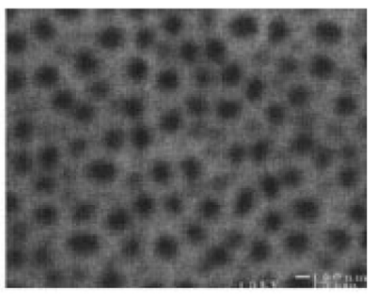

(d)

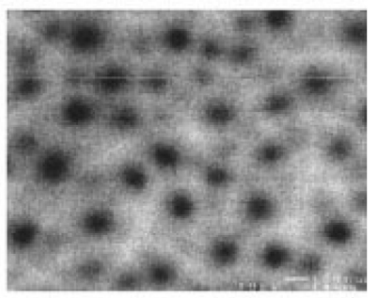

(e)

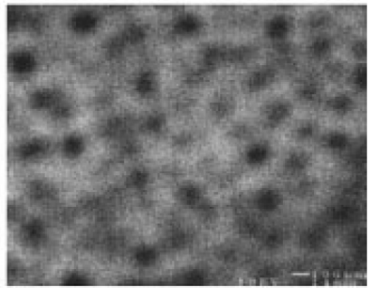

(f)

Figure 5. SEM images of porous templates prepared by anodization in $5 \%$ phosphoric acid at (a) $120 \mathrm{~V}$ (pore diameter order of $200 \mathrm{~nm}$ ), (b) $80 \mathrm{~V}$ (pore diameter order of $100 \mathrm{~nm}$ ), and (c) $40 \mathrm{~V}$ (pore diameter order of $60 \mathrm{~nm}$ ). The corresponding magnified images (d), (e), and (f), respectively, are also shown.

respectively. ${ }^{27,28}$ It may be added that appropriate self-ordering conditions are also essential for the growth of ideally ordered pore configuration. For example, in oxalic acid, pretexturing can lead to well-ordered pore arrays over very long ranges only at a voltage of about $40 \mathrm{~V}$. For other voltages, pretexturing cannot maintain ideal ordering over long ranges. In the case of phosphoric acid, Masuda et al. ${ }^{29}$ observed that the appropriate anodization voltage is $200 \mathrm{~V}$ to maintain long-range order on pretexturing. This is also the condition for naturally occurring long-range order in the absence of pretexturing. ${ }^{28}$ In the case of sulfuric acid the appropriate voltage is $20-25 \mathrm{~V}^{23,27}$ The appropriate voltage also depends on other conditions, such as concentration of electrolyte, temperature of solution, and so forth.

For anodization in $15 \%$ sulfuric acid, the pore diameters obtained are very small. Figure 9 shows TEM images of the templates anodized at two different voltages, 15 and $10 \mathrm{~V}$. For the $15 \mathrm{~V}$ sample, the pore diameter is of the order of $20 \mathrm{~nm}$. It decreases to about $10 \mathrm{~nm}$ for the $10 \mathrm{~V}$ sample. It may be noted that the anodization in sulfuric acid does not exhibit good periodicity in the porous structure. 


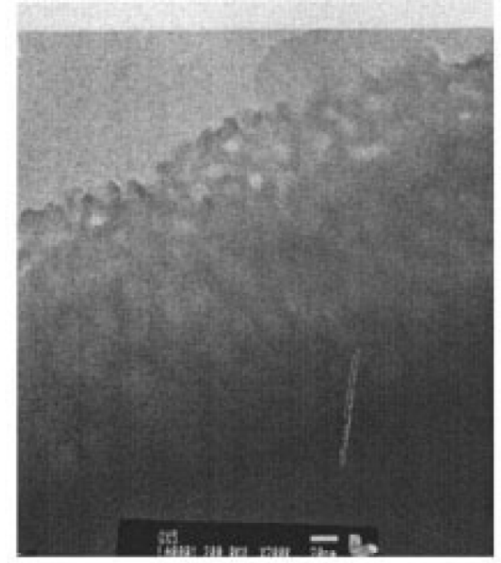

(a)

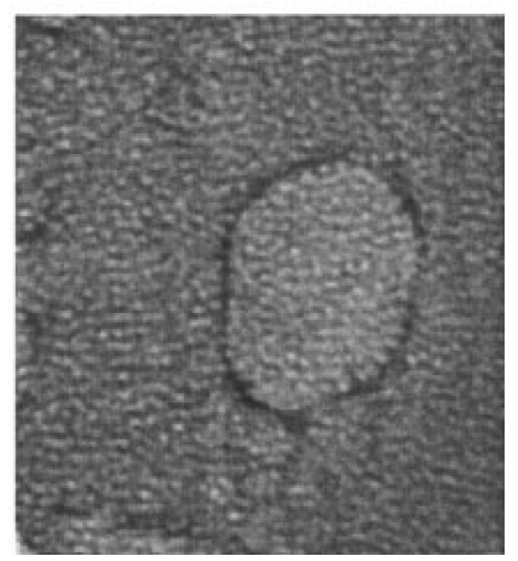

(b)

Figure 6. TEM image of templates prepared by anodization in $3 \%$ oxalic acid at (a) $5 \mathrm{~V}$ (pore diameter about $15 \mathrm{~nm}$ ) and (b) $10 \mathrm{~V}$ (pore diameter about $25 \mathrm{~nm}$ ).

Porous alumina templates may be used for nanosynthesis in many different ways. Two of the standard methods that are being used are now discussed.

\section{AC and DC Electrodeposition}

Porous alumina templates prepared as described above may then be used to manufacture nanowires using AC or DC electrodeposition. Because of the presence of the barrier layer of aluminum, AC electrodeposition must be used to directly electrodeposit nanowires into the pores. Alternatively, both the aluminum and the barrier layer may be removed by chemical means. The through-hole porous layer may then be coated with the material of choice, such as Pt, Au, and so forth. DC electrodeposition can then be used to synthesize the nanowires. DC electrodeposition is particularly useful in the preparation of multilayers, where it is necessary to control the depo- sition voltage to allow deposition of the appropriate element. Both DC and AC electrodeposition, however, suffer from the disadvantage that the wire lengths are not very uniform. Also, it is difficult to control the lengths to the order of angstroms, or even a few nanometers, which may be necessary in many applications. In addition, in several applications one would like to prepare self-assembled nanodots on materials other than aluminum. One way to achieve this is by using porous alumina templates as evaporation masks to prepare arrays of nanodots by e-beam evaporation. ${ }^{24} \mathrm{~A}$ two-step anodization of the $\mathrm{Al}$ foil is carried out at a constant voltage of $40 \mathrm{~V}$ in a $3 \%$ oxalic acid solution. In the first long step, the $\mathrm{Al}$ foil is anodized for a long time to create an ordered array of nanopores. The alumina layer is dissolved away in a mixture of chromicphosphoric acid and the pretextured $\mathrm{Al}$ foil is then reanodized for 3-4 min to create a very thin porous layer ( $\sim 0.5$ micron). The top surface of the film is then protected against etching

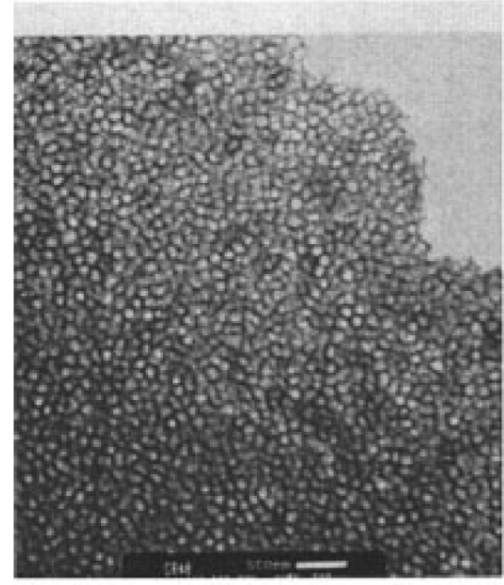

(a)

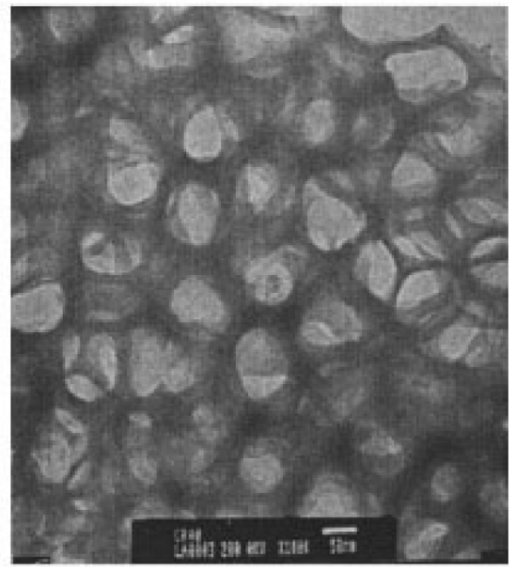

(b)

Figure 7. (a) TEM image of porous templates anodized in 5\% chromic acid at $40 \mathrm{~V}$ (pore diameter order of 70-100 nm); (b) magnified image of the same. 
(a)

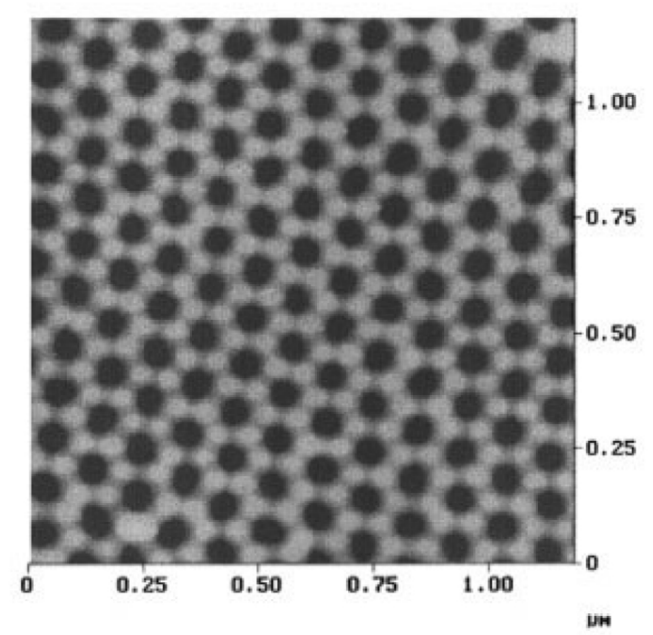

(b)

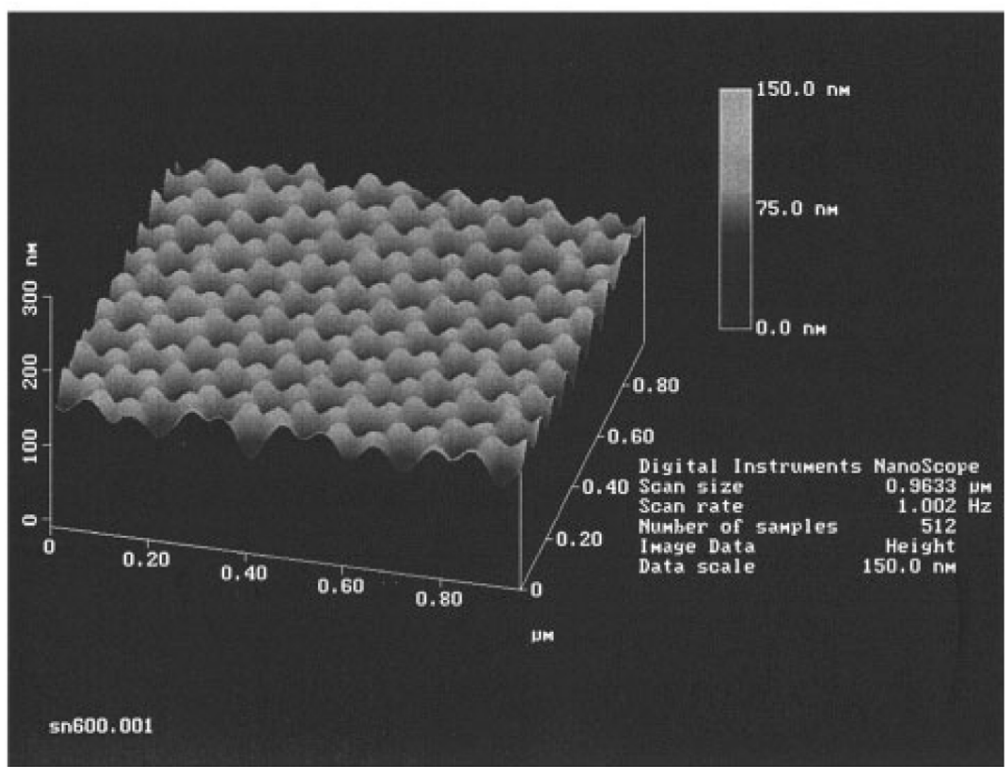

Figure 8. AFM image of a well-ordered pore array obtained after a two-step anodized sample in $3 \%$ oxalic acid at 40 V. Pore diameter order of $50 \mathrm{~nm}$. (a) Top and (b) 3D-surface views are shown below.

by coating with an organic layer. The bottom Al layer is removed in a saturated $\mathrm{HgCl}_{2}$ solution. The barrier layer of alumina below the porous layer is removed using $5 \mathrm{wt} \%$ phosphoric acid for about $60 \mathrm{~min}$. This leads to the formation of a membrane with an array of through holes. The thin throughhole layer is placed on a Si substrate and dried. E-beam evaporation is used to deposit a layer of Au on the Si substrate. Deposition through the mask leads to the formation of an array of Au dots on the Si substrate. Figure 10 shows an AFM image of such an array. The diameter of the dots is of the order of $65 \mathrm{~nm}$, whereas the height is $20 \mathrm{~nm}$. Such arrays of nanodots are expected to have applications in the fabrication of nanoelectronic devices.

Using the evaporation mask method, one can also conveniently prepare nanodots of multilayers, such as $\mathrm{Fe} / \mathrm{CdS} / \mathrm{Fe}$, $\mathrm{Fe} / \mathrm{Si} / \mathrm{Fe}$, and the like. Such multilayers have important appli- cations in spintronic devices and spin-based quantum computers. ${ }^{30,31}$ We are currently synthesizing such devices and our results will be discussed in future publications.

\section{Conclusions}

Porous alumina is one of the simplest methods to synthesize arrays of nanowires and nanodots. A variety of materialssemiconducting, superconducting, magnetic, and so forthcan easily be electrodeposited into the pores. Good control over the size of nanoparticles and the distribution of nanoarrays can be achieved by controlling the fabrication conditions. Porous alumina may also be used as evaporation masks. Arrays of nanodots and nanowires can thus be synthesized directly on the surface of silicon or any other material, allowing for potential applications in nanoelectronics.

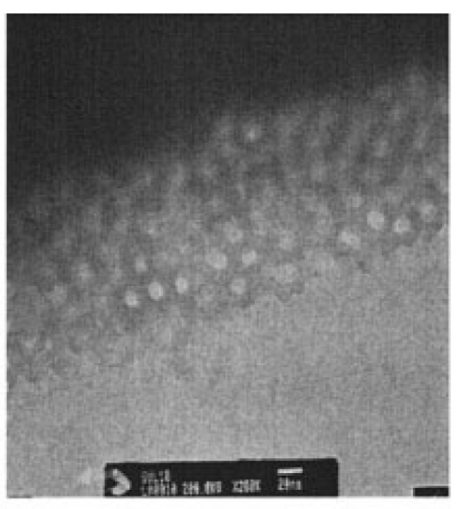

(a)

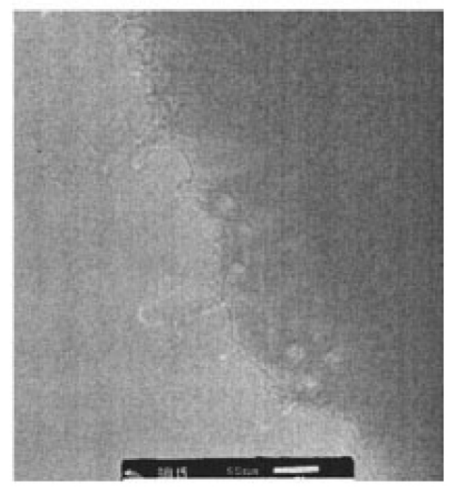

(b)

Figure 9. TEM images of porous templates prepared by anodization in $15 \%$ sulfuric acid. At (a) 10 $\mathrm{V}$, pore diameter is of the order of $10 \mathrm{~nm}$; and (b) $15 \mathrm{~V}$, pore diameter is of the order of $20 \mathrm{~nm}$. 


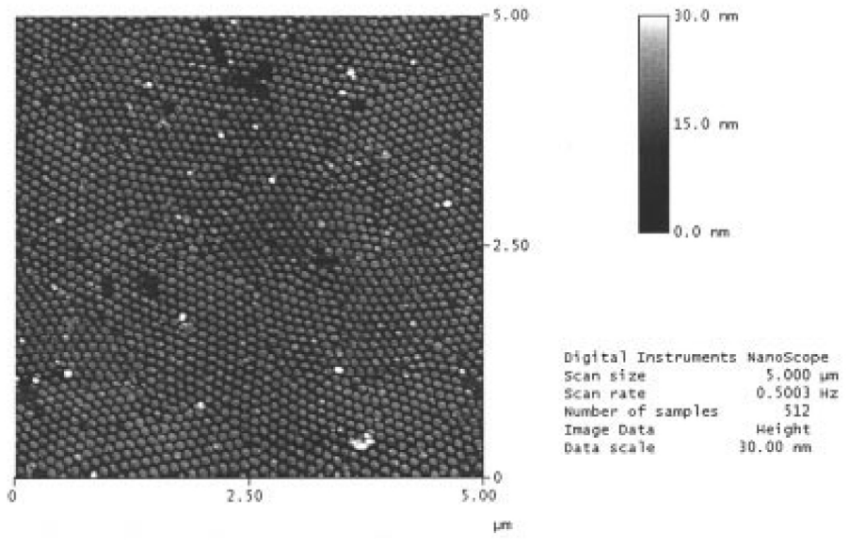

Figure 10. AFM image of an array of Au nanodots on the surface of silicon prepared by using porous alumina as a mask. Diameter of nanodots is of the order of $65 \mathrm{~nm}$ and height is $20 \mathrm{~nm}$.

\section{References}

1 Bengough GD, Stuart JM. A process for producing a coloured surface on aluminium or aluminium alloys. Br. Patent No. 223995; 1924.

2 Menon L. Nanoarrays from porous alumina. The Dekker Encyclopedia of Nanoscience and Nanotechnology. New York, NY: Marcel-Dekker Publishers; 2004: 2221-2235.

3 Diggle JW, Downie TC, Goulding CW. Anodic oxide films on aluminum. Chem. Rev. 1969; 69: 365-405.

4 Moskovits M. Process for manufacture of quantum dot and quantum wire semiconductors. Int. Patent No. 5202290; 1993.

5 Martin CR. Nanomaterials - A membrane-based synthetic approach. Science. 1994; 266: 1961-1966.

6 Routkevich D, Tager AA, Haruyama J, Almawlawi D, Moskovits $\mathrm{M}, \mathrm{Xu}$ JM. Non-lithographic nanowire arrays: Fabrication, physics and device applications. IEEE Trans. Electron. Dev. 1996; 43: $1646-1658$.

7 Menon L, Zheng M, Zeng H, Sellmyer DJ, Bandyopadhyay S. Size dependence of the magnetic properties of electrochemically self-assembled Fe quantum dots. J. Electron. Mater. 2000; 29: 510-514.

8 Zeng H, Zheng M, Skomski R, Sellmyer DJ, Menon L, Bandyopadhyay S. Magnetic properties of self-assembled Co nanowires with varying length and diameter. J. Appl. Phys. 2000; 87: 4718-4720.

9 Zheng M, Menon L, Zeng H, Liu Y, Bandyopadhyay S, Kirby RD, Sellmyer DJ. Magnetic properties of Ni nanowires in selfassembled arrays. Phys. Rev. 2000; B62: 12282-12286.

10 Kouklin N, Menon L, Wong AZ, Thompson DW, Woollam JA, Williams PF, Bandyopadhyay S. Giant photoresistivity and optically controlled switching in self-assembled nanowires. Appl. Phys. Lett. 2001; 79: 4423-4425.

11 Kouklin N, Menon L, Bandyopadhyay S. Room temperature single-electron charging in electrochemically synthesized semiconductor quantum dot and wire array. Appl. Phys. Lett. 2002; 80: 1649-1651.

12 Keller F, Hunter MS, Robinson DL. Structural features of oxide coatings on aluminium. J. Electrochem. Soc. 1953; 100: 411.
13 Lohrengel MM. Thin anodic oxide layers on aluminum and other valve metals: High field regime. Mater. Sci. Eng. 1993; R11: 243.

14 Bandyopadhyay S, Miller AE, Chang HC, Banerjee G, Yuzhakov V, Yue DF, Ricker RE, Jones S, Eastman JA, Baugher E, Chandrasekhar M. Electrochemically assembled quasi-periodic quantum dot arrays. Nanotechnology. 1996; 7: 360-371.

15 Konovalov VV, Metzger RM, Zangari G. Electrochemical technology applications in electronics. J. Electrochem. Soc. 2000; PV99-34: 203.

16 Tada T, Kanayama T, Koga K, Weibel P, Carroll SJ, Seeger K, Palmer RE. Formation of $10 \mathrm{~nm}$ Si structures using size-selected metal clusters. J. Phys. 1998; D31: L21-L34.

17 Li F, Zhang L, Metzger M. On the growth of highly ordered pores in anodized aluminum oxide. Chem. Mater. 1998; 10: 2473.

18 O'Sullivan, Wood GC. The morphology and the mechanism of formation of porous anodic films on aluminium. Proc. R. Sci. Soc. 1970; A317: 511-543.

19 Parkhutik VP, Shershulsky VI. Theoretical modeling of porous oxide growth on aluminum. J. Phys. D: Appl. Phys. 1992; 25: 1258-1263.

20 Siejka J, Ortega C. An O 18 study of field-assisted pore formation in compact oxide films on aluminium. J. Electrochem. Soc. 1977; 124: 883-891.

21 Thompson GE, Wood GC. Anodic films on aluminum. In: Scully JC , ed. Treatise on Material Science and Technology. New York, NY: Academic Press; 1983: 205.

22 Shimizu K, Kobayashi K, Thompson GE, Wood GC. A novel marker for the determination of transport numbers during anodic oxide barrier growth of aluminum. Philos. Mag. B. 1991; 64: 345 .

23 Jessensky O, Múller F, Gósele U. Self-organized formation of hexagonal pore arrays in anodic alumina. Appl. Phys. Lett. 1998; 72: 1173-1175.

24 Masuda H, Satoh M. Fabrication of gold nanodot array using anodic porous alumina as an evaporation mask. Jpn. J. Appl. Phys. 1996; 35: L126.

25 Masuda H, Fukuda K. Ordered metal nanohole arrays made by a two-step replication of honeycomb structures of anodic alumina. Science. 1995; 268: 1466-1468.

26 Li AP, Muller F, Birner A, Nielsch K, Gosele U. Hexagonal pore arrays with a $50-420 \mathrm{~nm}$ interpore distance formed by self-organization in anodic alumina. J. Appl. Phys. 1998; 84: 6023-6026.

27 Masuda H, Hasegawa F, Ono S. Self-ordering of cell arrangement of anodic porous alumina formed in sulfuric acid solution. J. Electrochem. Soc. 1997; 144: L127-L130.

28 Masuda H, Yada K, Osaka A. Self-ordering of cell configuration of anodic porous alumina with large-sized pores in phosphoric acid solution. Jpn. J. Appl. Phys. 1998; 37: L1340.

29 Asoh H, Nishio K, Nakao M, Tamamura T, Masuda H. Conditions for fabrication of ideally ordered anodic porous alumina using pretextured Al. J. Electrochem. Soc. 2001; 148: B152-B156.

30 Gershenfeld NA, Chuang LA. Bulk spin-resonance quantum computation. Science. 1997; 275: 350-356.

31 Bandyopadhyay S. Self-assembled nanoelectronic quantum computer based on the Rashba effect in quantum dots. Phys. Rev. B. 2000; 61: 13813-13820. 